\title{
Early Stages of Precipitation Process in Al-(Mn-)Sc-Zr Alloy Characterized by Positron Annihilation
}

\author{
MARTIN VLACH, JAKUB CIZEK, OKSANA MELIKHOVA, IVANA STULIKOVA, \\ BOHUMIL SMOLA, TOMAS KEKULE, HANA KUDRNOVA, RYOTA GEMMA, \\ and VOLKMAR NEUBERT
}

\begin{abstract}
Thermal effects on the precipitation stages in as-cast Al-0.70 at. pct Mn-0.15 at. pct Sc-0.05 at. pct $\mathrm{Zr}$ alloy were studied. The role of lattice defects was elucidated by positron annihilation spectroscopy (lifetime and coincidence Doppler broadening) enabling investigation of solutes clustering at the atomic scale. This technique has never been used in the Al-Sc- and/or Al-Zr-based alloys so far. Studies by positron annihilation were combined with resistometry, hardness measurements, and microstructure observations. Positrons trapped at defects are preferentially annihilated by Sc electrons. Lifetime of trapped positrons indicates that Sc atoms segregate at dislocations. Maximum fraction of positrons annihilated by Sc electrons occurring at $453 \mathrm{~K}\left(180^{\circ} \mathrm{C}\right)$ suggests that clustering of Sc bound with vacancies takes place. It is followed by peak of this fraction at $573 \mathrm{~K}\left(300^{\circ} \mathrm{C}\right)$. A rise of the contribution of trapped positrons annihilated by $\mathrm{Zr}$ electrons starting at $513 \mathrm{~K}\left(240^{\circ} \mathrm{C}\right)$ and attaining maximum also at $573 \mathrm{~K}$ $\left(300{ }^{\circ} \mathrm{C}\right)$ confirms that $\mathrm{Zr}$ participates in precipitation of the $\mathrm{Al}_{3} \mathrm{Sc}$ particles already at these temperatures. The pronounced hardening at $573 \mathrm{~K}\left(300^{\circ} \mathrm{C}\right)$ has its nature in the precipitation of the $\mathrm{Al}_{3} \mathrm{Sc}$ particles with a $\mathrm{Zr}$-rich shell. The contribution of trapped positrons annihilated by $\mathrm{Mn}$ electrons was found to be negligible.
\end{abstract}

DOI: $10.1007 / \mathrm{s} 11661-015-2767-\mathrm{x}$

(C) The Minerals, Metals \& Materials Society and ASM International 2015

\section{INTRODUCTION}

AL-BASED alloys-containing Sc are promising materials for high-temperature structural applications. ${ }^{[1-3]}$ A number of investigations have been carried out in Al-based alloys-containing $\mathrm{Mn}, \mathrm{Sc}$, and $\mathrm{Zr}, e . g$, References 4 through 8 . The promising results are related to the formation of a dense and homogeneous distribution of the $\mathrm{Ll}_{2}$-structured $\mathrm{Al}_{3}(\mathrm{Sc}, \mathrm{Zr})$ precipitates. ${ }^{[2-7,9-11]}$ The complex nanostructure of the $\mathrm{Al}_{3}(\mathrm{Sc}, \mathrm{Zr})$ phase in aluminum has been discussed in several recent articles by studies using conventional and high-resolution transmission electron microscopy (TEM) ${ }^{[12,13]}$ Atom-probe tomography (APT) was also employed to measure $\mathrm{Sc}, \mathrm{Zr}$ concentration and distribution. ${ }^{[14-16]}$ APT has shown that Sc-rich clusters can be formed in the early stages of precipitation above annealing temperatures of $\sim 523 \mathrm{~K}\left(250{ }^{\circ} \mathrm{C}\right) .{ }^{[15]}$ These clusters subsequently transform into the $\mathrm{Al}_{3} \mathrm{Sc}$ particles with the $\mathrm{Ll}_{2}$ structure. When $\mathrm{Zr}$ diffusion becomes

MARTIN VLACH, OKSANA MELIKHOVA, TOMAS KEKULE, and HANA KUDRNOVA, Researchers, JAKUB CIZEK, IVANA STULIKOVA, and BOHUMIL SMOLA, Associate Professors, are with the Faculty of Mathematics and Physics, Charles University in Prague, Ke Karlovu 3, 12116 Prague, Czech Republic. Contact e-mail: martin.vlach@mff.cuni.cz RYOTA GEMMA, Researcher, is with the Physical Sciences and Engineering Division, King Abdullah University of Science and Technology (KAUST), Thuwal 23955-6900, Saudi Arabia. VOLKMAR NEUBERT, Professor, is with the Institut für Materialprüfung und Werkstofftechnik, Freiberger Strasse 1, 38678 Clausthal-Zellerfeld, Germany.

Manuscript submitted July 21, 2014.

Article published online 29 January 2015 significant, $\mathrm{Zr}$ atoms are found to segregate to $\mathrm{Al}_{3} \mathrm{Sc} / \alpha$ $\mathrm{Al}$ matrix interfaces. During further annealing $[\sim 673 \mathrm{~K}$ $\left(400{ }^{\circ} \mathrm{C}\right)$ ] dispersoids with complex core-shell structure consisting of an $\mathrm{Al}_{3} \mathrm{Sc}$ core embedded in an $\mathrm{Al}_{3}(\mathrm{Sc}, \mathrm{Zr})$ shell are developed. ${ }^{[4,5,14,15]}$ Authors of the present study have already provided resistivity measurements of the Al-Sc-Zr alloy which showed that $\mathrm{Zr}$-segregation to the $\mathrm{Al}_{3} \mathrm{Sc} / \alpha$-Al matrix interfaces might take place already at $\sim 573 \mathrm{~K}\left(300{ }^{\circ} \mathrm{C}\right) .{ }^{[17]}$

Electrical resistivity measurement is a convenient way to follow precipitation kinetics in phase-separating systems ${ }^{[18,19]}$ as electrical resistivity having its origin in the scattering of free electrons by phonons and lattice defects reflects the material phase composition very sensitively. In general, clusters can be universally abundant in Al-based alloys and are known to affect the resistivity. Many authors have attempted to explain changes of electrical resistivity at the beginning of the precipitation kinetics (e.g., References 20 through 22). Clouet et al. ${ }^{[22]}$ modeled electrical resistivity evolution in Al-Sc-based alloys using cluster dynamics supposing that the excess resistivity caused by clusters is proportional to their number density. The proportionality coefficient was assumed to be constant and equal to the resistivity contribution of monomers. However, an increase in the resistivity at the beginning of the precipitation kinetics predicted by theoretical modeling has never been observed experimentally in an Al-Sc alloy. ${ }^{[2,23-25]}$ In our previous study, ${ }^{[20]}$ we observed even a small resistivity decrease at the beginning of supersaturated solid solution decomposition in the ternary Al-Sc-Zr alloy after annealing up to $\sim 513 \mathrm{~K}\left(240{ }^{\circ} \mathrm{C}\right)$. 
This paper attempts to enlarge the knowledge about the early precipitation stages, precipitation mechanisms and dynamics in the AlMnScZr alloy during nonisothermal annealing by positron annihilation spectroscopy (PAS) enabling to investigate clustering of solute atoms at the atomic scale. Two complementary PAS techniques were employed in the present work: (i) positron lifetime (LT) spectroscopy ${ }^{[26]}$ which enables to identify open volume defects in the sample and (ii) coincidence Doppler broadening $(\mathrm{CDB})^{[27]}$ which carries information about a local chemical environment of defects. CDB is a unique technique for investigation of early stages of precipitation and has been successfully employed for studies of this phenomenon, e.g., in $\mathrm{Fe}$ $\mathrm{Cu}^{[28]}$ and $\mathrm{Al}-\mathrm{Cu}$ alloys. ${ }^{[29]}$ But it has never been used in the Al-Sc- and/or Al-Zr-based alloys so far.

\section{MATERIALS AND METHODS}

The chemical composition of the as-cast AlMnScZr alloy was determined as: 0.699 at. pct (1.410 wt. pct) Mn, 0.153 at. pct (0.253 wt. pct) Sc, 0.047 at. pct (0.157 wt. pct) Zr, 0.006 at. pct (0.012 wt. pct) Fe, 0.008 at. pet $(0.008$ wt. pet) $\mathrm{Si}$ and $\mathrm{Al}$ balanced. The composition of the alloy was very close to the composition of the alloy used in Reference 5.

The isochronal annealing from room temperature (RT) up to $663 \mathrm{~K}\left(390^{\circ} \mathrm{C}\right)$ was performed in steps 30 $\mathrm{K} / 30 \mathrm{~min}$ in the same way as in References $4,5,17$. The samples were annealed in oil bath [up to $513 \mathrm{~K}\left(240{ }^{\circ} \mathrm{C}\right)$ ] or in a furnace with argon protective atmosphere. Each annealing step was finished by quenching into liquid nitrogen or water, respectively, in order to preserve the microstructure developed during the annealing. Highpurity Al (99.999 pct), Mn (99.95 pct), Sc (99.9 pct), and $\mathrm{Zr}$ (99.9 pct) specimens as reference were used, too.

Positron source utilized in LT and CDB measurements was made of as a small drop of ${ }^{22} \mathrm{Na}$ carbonate with activity of $1 \mathrm{MBq}$ (iThemba LABS) deposited and dried between the 2- $\mu \mathrm{m}$-thick Mylar C (DuPont) covering foils.

The LT measurements were carried out using a digital spectrometer described in Reference 30. The spectrometer was equipped with $\mathrm{BaF}_{2}$ scintillators and Hamamatsu H3378 photomultipliers and exhibited a time resolution of 145 ps (FWHM of the resolution function for $\left.{ }^{22} \mathrm{Na}\right)$. Typically, $10^{7}$ coincidence events were accumulated in each LT spectrum. The LT spectra were decomposed into the discrete components by means of a procedure $^{[31]}$ based on the maximum-likelihood principle. A contribution of positron annihilations in the source salt and covering foils was determined using a well-annealed high-purity Al specimen.

The CDB investigations were performed using a digital spectrometer ${ }^{[32]}$ equipped with two high-purity Ge detectors and characterized by energy resolution of $0.9 \mathrm{KeV}$ at $511 \mathrm{KeV}$. The two dimensional CDB energy spectra were reduced into one-dimensional cuts representing the Doppler broadened (DB) annihilation profiles. In this paper, the DB profiles are presented as the ratio curves related to the well-annealed pure $\mathrm{Al}$ reference specimen.
The electrical resistivity measurements were performed at $78 \mathrm{~K}$ in liquid $\mathrm{N}_{2}$ bath by means of the direct current four-point method with a dummy specimen in series. The effect of a parasitic thermo-electromotive force was suppressed by changing the current polarity. The deformation of electrical field in the vicinity of contacts was estimated, yielding the total accuracy better than $\sim 2$ pet. ${ }^{[33]}$

The Vickers hardness HV10 measurements were performed at RT using a load of $10 \mathrm{~kg}$ and a loading time of 10 seconds.

TEM and electron diffraction (ED) were carried out to determine the microstructure in the selected states of material. The analysis of precipitated phases was complemented by energy-dispersive spectroscopy performed by X-ray BRUKER microanalyser.

\section{RESULTS}

\section{A. As-cast State of the AlMnScZr Alloy}

The annealed high-purity Al, Sc, Zr, and Mn specimens exhibit single-component LT spectra with lifetimes $(160.7 \pm 0.5), \quad(196.0 \pm 1.0), \quad(161.5 \pm 0.5), \quad$ and $(109.0 \pm 1.0)$ ps which are in good agreement with the bulk lifetimes for these materials obtained by ab initio theoretical calculations. ${ }^{[34]}$ Hence, in the well-annealed specimens practically all positrons are annihilated from the free state (not trapped at defects), and the samples can be therefore considered as virtually defect-free materials.

The CDB ratio curves for the well-annealed highpurity $\mathrm{Mn}, \mathrm{Sc}$, and $\mathrm{Zr}$ are plotted in Figure 1. Note that the ratio curve for the well-annealed high-purity $\mathrm{Al}$ is just a straight line at unity since all ratio curves are related to this specimen. The ratio curve for Sc exhibits a local minimum at $p \approx 5 \times 10^{-3} \mathrm{~m}_{0} \mathrm{c}$, followed by a local maximum at $p \approx 9 \times 10^{-3} \mathrm{~m}_{0} \mathrm{c}$. The ratio curve for pure $\mathrm{Zr}$ is characterized by a maximum at $p \approx 9 \times$ $10^{-3} \mathrm{~m}_{0} \mathrm{c}$, which is higher than that for $\mathrm{Sc}$ and it is followed by a broad peak centered at $p \approx 30 \times$ $10^{-3} \mathrm{~m}_{0} \mathrm{c}$. The ratio curve for $\mathrm{Mn}$ is characterized by a strong peak at $p \approx 10.5 \times 10^{-3} \mathrm{~m}_{0} \mathrm{c}$ with a slowly decaying tail at high momentum.

The as-cast AlMnScZr alloy exhibits two-component LT spectrum: the shorter component with lifetime $\tau_{1}=$ $(146 \pm 3) \mathrm{ps}$ and relative intensity $I_{1}=(27 \pm 1) \mathrm{pct}$ comes from free positrons not trapped at defects. Note that the lifetime $\tau_{1}$ is shortened below the positron bulk lifetime for $\mathrm{Al}\left(\tau_{\mathrm{B}}=160.7 \mathrm{ps}\right)$ due to presence of defects. As described by the simple trapping model, ${ }^{[35]}$ the lifetime $\tau_{1}$ is governed by the relation $1 / \tau_{1}=$ $1 / \tau_{\mathrm{B}}+K$, where $K$ is the positron trapping rate proportional to the defect concentration. The longer component with the lifetime $\tau_{2}=(250 \pm 5)$ ps and intensity $I_{2}=(73 \pm 1)$ pct represents a contribution of positrons trapped at defects. Since the lifetime $\tau_{2}$ agrees well with that reported for dislocations in $\mathrm{Al},{ }^{[36,37]}$ we can attribute this component to positrons trapped at dislocations created in the as-cast sample most probably due to non-uniform cooling of the cast ingot. Microstructure observations of the as-cast alloy by TEM proved the presence of dislocations (Figure 2). No second-phase 


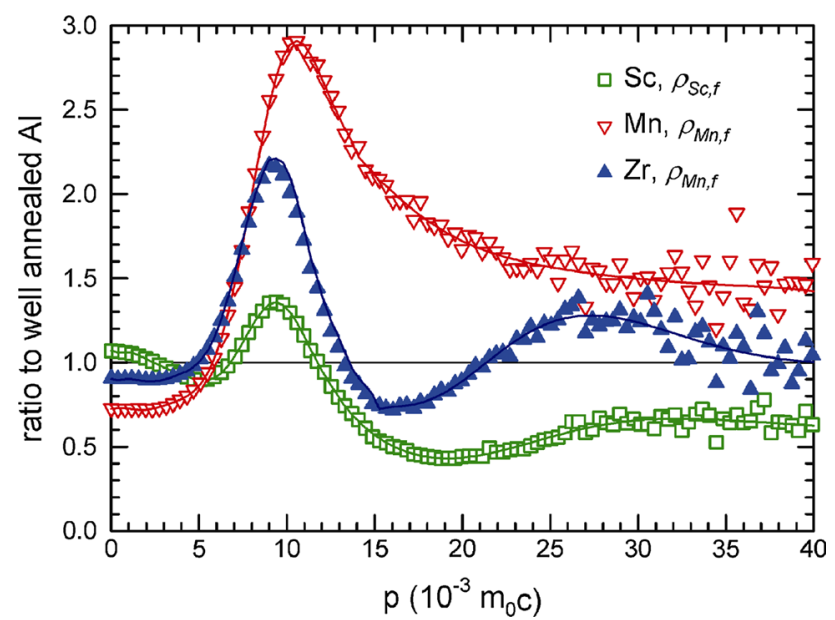

Fig. 1-CDB ratio curves for well-annealed high-purity Sc, Mn, and Zr.

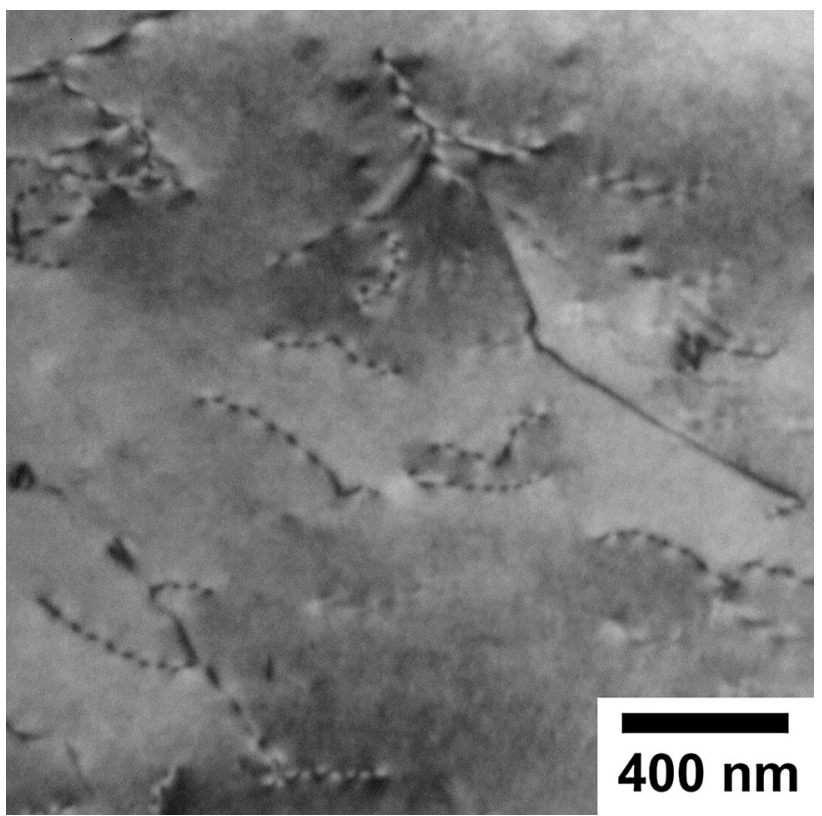

Fig. 2-TEM bright field image of the as-cast AlMnScZr alloy.

particles were observed. The mean dislocation density $\rho_{\mathrm{D}}$ in the sample can be estimated using the two-state trapping model ${ }^{[35]}$ :

$$
\rho_{\mathrm{D}}=\frac{I_{2}}{v_{\mathrm{D}}}\left(\frac{1}{\tau_{1}}-\frac{1}{\tau_{2}}\right)
$$

where $v_{\mathrm{D}}$ is the specific positron trapping rate for dislocations in Al. Using $v_{\mathrm{D}}=5 \times 10^{-5} \mathrm{~m}^{2} \mathrm{~s}^{-1},{ }^{[38]}$ the Eq. [1] yields the mean dislocation density $\rho_{\mathrm{D}}=(4 \pm 1) \times$ $10^{13} \mathrm{~m}^{-2}$ in the as-cast AlMnScZr alloy.

\section{B. Positron Annihilation Study During Isochronal Annealing}

The development of the lifetimes $\tau_{1}, \tau_{2}$ with increasing annealing temperature is plotted in Figure 3(a), while

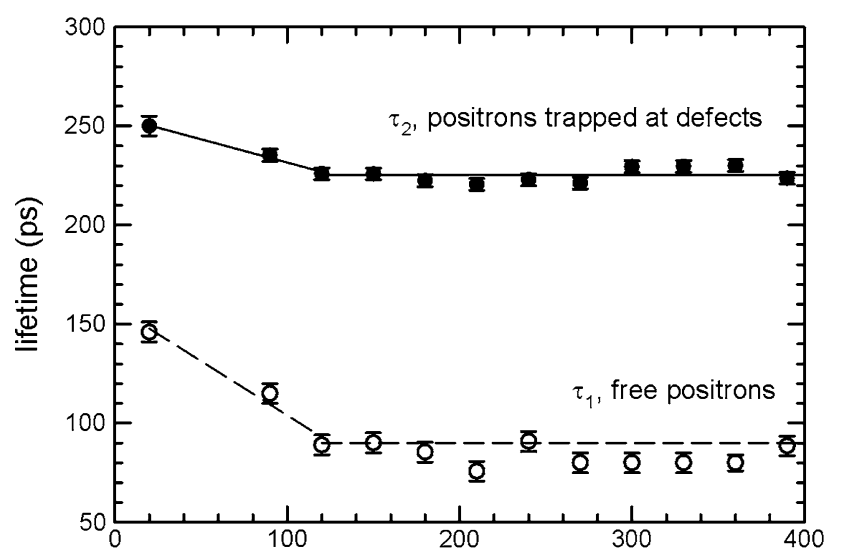

(a)

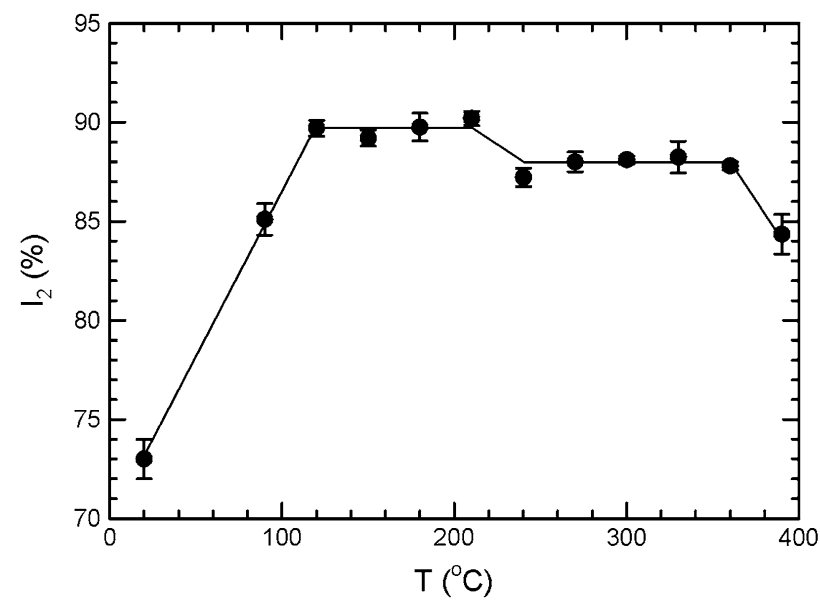

(b)

Fig. 3-Temperature dependence of (a) lifetimes of components resolved in LT spectra, $(b)$ intensity $I_{2}$ of positrons trapped at defects.

Figure 3(b) shows temperature dependence of the intensity $I_{2}$ of positrons trapped at defects. It can be seen that annealing of the as-cast alloy up to $393 \mathrm{~K}\left(120^{\circ} \mathrm{C}\right)$ leads to a decrease of $\tau_{1}$ accompanied by an increase of $I_{2}$. It testifies that new defects were created in the sample in addition to dislocations. Since the lifetime $\tau_{2}$ of trapped positrons is not constant but exhibits a slight decrease the new defects are characterized by a lifetime slightly shorter than that for dislocations. There is a general agreement (see Reference 39) that a dislocation line itself is only a shallow positron trap and positrons trapped at dislocations diffuse quickly along the dislocation line and become finally trapped at vacancies anchored in the compressive elastic field of dislocations. Hence, at temperatures above $\sim 393 \mathrm{~K}\left(120^{\circ} \mathrm{C}\right)$, the component $\tau_{2}$ contains a contribution from positrons trapped at dislocations and also a contribution of positrons trapped at the new defects with open volume smaller than that for a single vacancy in Al. The new defects are most probably vacancies associated with solute atoms. Hence, enhanced intensity $I_{2}$ in the temperature range of $393 \mathrm{~K}$ to $473 \mathrm{~K}$ $\left(120{ }^{\circ} \mathrm{C}\right.$ to $\left.200{ }^{\circ} \mathrm{C}\right)$ indicates that a precipitation process in this temperature range leads to formation of new vacancy-like defects associated with solutes. The intensity 


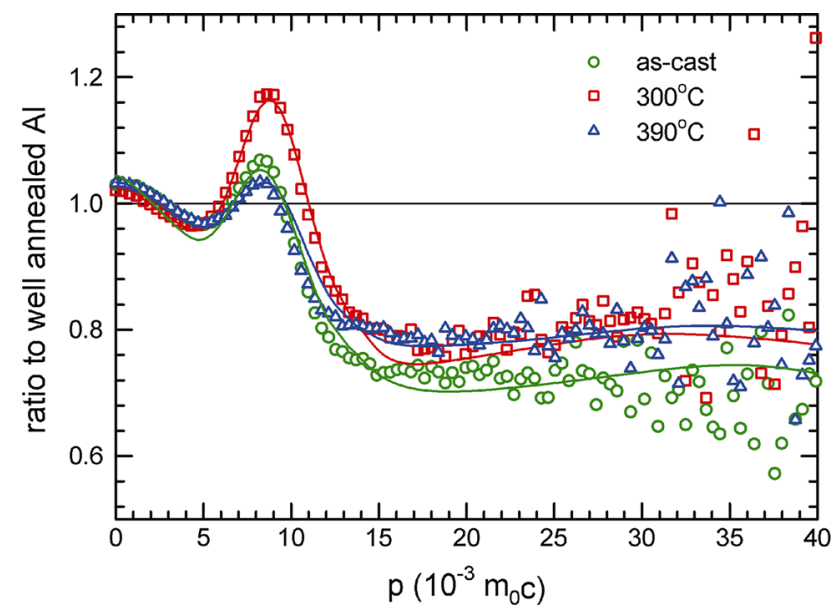

Fig. 4- CDB ratio curves for the AlMnScZr alloy in the as-cast state and selected annealed states [up to $573 \mathrm{~K}$ and $663 \mathrm{~K}\left(300{ }^{\circ} \mathrm{C}\right.$ and $390{ }^{\circ} \mathrm{C}$ )]. Solid lines show model curves calculated by Eq. [4].

$I_{2}$ exhibits a drop at $513 \mathrm{~K}\left(240{ }^{\circ} \mathrm{C}\right)$ indicating a decrease of the defect density and/or coarsening of the precipitates. A further drop was observed at $653 \mathrm{~K}\left(380{ }^{\circ} \mathrm{C}\right)$ which is most probably caused by further coarsening and dissolution of the precipitates.

The CDB ratio curves for the AlMnScZr alloy in the as-cast state and selected annealed states $[573 \mathrm{~K}$ and $663 \mathrm{~K}\left(300{ }^{\circ} \mathrm{C}\right.$ and $\left.390{ }^{\circ} \mathrm{C}\right)$ ] are plotted in Figure 4. Obviously the curves for AlMnScZr alloy exhibit a minimum at $p \approx 5 \times 10^{-3} \mathrm{~m}_{0} \mathrm{c}$ and a peak at $p \approx 9 \times$ $10^{-3} \mathrm{~m}_{0} \mathrm{c}$. Compared to Figure 1, this indicates that positrons are preferentially annihilated by Sc electrons. The contribution of positrons annihilated by $\mathrm{Mn}$ electrons can be considered as negligible but one cannot exclude that some fraction of positrons is annihilated by $\mathrm{Zr}$ electrons.

Figure 5 shows the development of CDB ratio curves with increasing annealing temperature. There are two distinguishable stages at $\sim 453 \mathrm{~K}\left(180{ }^{\circ} \mathrm{C}\right)$ (labeled as I-CDB stage) and $\sim 573 \mathrm{~K}\left(300{ }^{\circ} \mathrm{C}\right)$ (labeled as II-CDB stage) which indicate that precipitation of Sc-rich and/or Zr-rich particles takes place there.

To obtain quantitative information about Sc- and $\mathrm{Zr}$ rich phase precipitation, the ratio curves for $\mathrm{AlMnScZr}$ alloy were fitted by a superposition of the curves for the corresponding pure elements. In the decomposition of a ratio curve for AlMnScZr alloy, it should be considered that positrons are annihilated in two states: either in the free state or in the localized state at open volume defects. Hence, the CDB ratio curve $\rho(p)$ for $\mathrm{AlMnScZr}$ alloy can be expressed as following:

$$
\begin{aligned}
\rho(p)= & F_{\mathrm{f}}\left(\xi_{\mathrm{Al}, \mathrm{f}}+\xi_{\mathrm{Sc}, \mathrm{f}} \rho_{\mathrm{Sc}, \mathrm{f}}(p)+\xi_{\mathrm{Zr}, \mathrm{f}} \rho_{\mathrm{Zr}, \mathrm{f}}(p)\right. \\
& \left.+\xi_{\mathrm{Mn}, \mathrm{f}} \rho_{\mathrm{Mn}, \mathrm{f}}(p)\right)+F_{\mathrm{D}}\left(\xi_{\mathrm{Al}, \mathrm{D}} \rho_{\mathrm{Al}, \mathrm{D}}(p)\right. \\
& \left.+\xi_{\mathrm{Sc}, \mathrm{D}} \rho_{\mathrm{Sc}, \mathrm{D}}(p)+\xi_{\mathrm{Zr}, \mathrm{D}} \rho_{\mathrm{Zr}, \mathrm{D}}(p)+\xi_{\mathrm{Mn}, \mathrm{D}} \rho_{\mathrm{Mn}, \mathrm{D}}(p)\right)
\end{aligned}
$$

where $F_{\mathrm{f}}$ and $F_{\mathrm{D}}$ denote the fraction of positrons annihilated in the free and the trapped state, respectively, and they are normalized so that $F_{\mathrm{f}}+F_{\mathrm{D}}=1$.

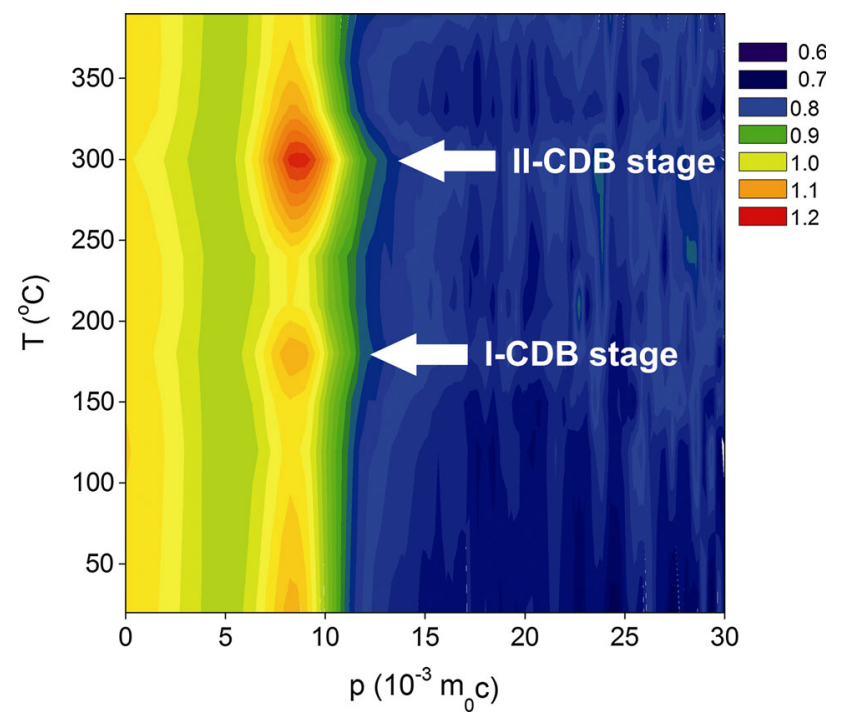

Fig. 5-The development of CDB ratio curves for AlMnScZr alloy with increasing annealing temperature. Color coded $z$-axis is the ratio with respect to well-annealed $\mathrm{Al}$ reference.

The fraction $F_{\mathrm{D}}$ can be calculated from the results of LT measurements using the two-state trapping $\operatorname{model}^{[35]}$ :

$$
F_{\mathrm{D}}=I_{2} \frac{\tau_{2}-\tau_{\mathrm{B}}}{\tau_{2}-I_{2} \tau_{\mathrm{B}}}
$$

and it is plotted in Figure 6 as a function of the annealing temperature. The symbol $\tau_{\mathrm{B}}$ stands for the bulk lifetime, i.e., lifetime of free positrons in a defects-free material, the symbols $\rho_{\mathrm{Sc}, \mathrm{f}}(p), \rho_{\mathrm{Zr}, \mathrm{f}}(p)$, and $\rho_{\mathrm{Mn}, \mathrm{f}}(p)$ denote the CDB ratio curves for free positrons annihilated by $\mathrm{Sc}, \mathrm{Zr}$, and Mn electrons. Similarly the symbols $\rho_{\mathrm{Al}, \mathrm{D}}(p), \rho_{\mathrm{Sc}, \mathrm{D}}(p)$, $\rho_{\mathrm{Zr}, \mathrm{D}}(p)$, and $\rho_{\mathrm{Mn}, \mathrm{D}}(p)$ denote the CDB ratio curves for trapped positrons annihilated by $\mathrm{Al}, \mathrm{Sc}, \mathrm{Zr}$, and $\mathrm{Mn}$ electrons. The coefficients $\xi_{x, \mathrm{f}}$ (where $x=\mathrm{Al}, \mathrm{Sc}, \mathrm{Zr}$, $\mathrm{Mn})$ denote the probabilities that a free positron is annihilated by $\mathrm{Al}, \mathrm{Sc}, \mathrm{Zr}$, or $\mathrm{Mn}$ electron. These probabilities fulfill the normalization condition $\xi_{\mathrm{Al}, \mathrm{f}}+$ $\xi_{\mathrm{Sc}, \mathrm{f}}+\xi_{\mathrm{Zr}, \mathrm{f}}+\xi_{\mathrm{Mn}, \mathrm{f}}=1$. Similarly the coefficients $\xi_{x, \mathrm{D}}$ (where $x=\mathrm{Al}, \mathrm{Sc}, \mathrm{Zr}, \mathrm{Mn}$ ) stand for the probabilities that trapped positrons are annihilated by Al, Sc, Zr, and Mn electrons. Again these coefficients obey the normalization condition $\xi_{\mathrm{Al}, \mathrm{D}}+\xi_{\mathrm{Sc}, \mathrm{D}}+\xi_{\mathrm{Zr}, \mathrm{D}}+\xi_{\mathrm{Mn}, \mathrm{D}}=1$.

If all alloying elements are dissolved in Al matrix, the coefficients $\xi_{x, \mathrm{f}}$ equal to their atomic concentration in the alloy. Hence, $\xi_{\mathrm{Sc}, \mathrm{f}}=1.53 \times 10^{-3}, \xi_{\mathrm{Zr}, \mathrm{f}}=4.7 \times 10^{-4}$, $\xi_{\mathrm{Mn}, \mathrm{f}}=6.99 \times 10^{-3}$ represent here the upper limits of these probabilities corresponding to the case when Mn, $\mathrm{Sc}$, and $\mathrm{Zr}$ are fully dissolved in Al matrix. These values are so low that the probability that a free positron will be annihilated by Sc, Zr, or Mn electron can be considered as negligible. In other words, the fact that ratio curves for the AlMnScZr alloys differ significantly from unity and exhibit a peak at $p \approx 9 \times 10^{-3} \mathrm{~m}_{0} \mathrm{c}$ testifies that local chemical environment of defects is substantially enriched by $\mathrm{Sc}$ and/or Zr. Hence, Eq. [2] can be written in a more simple form 


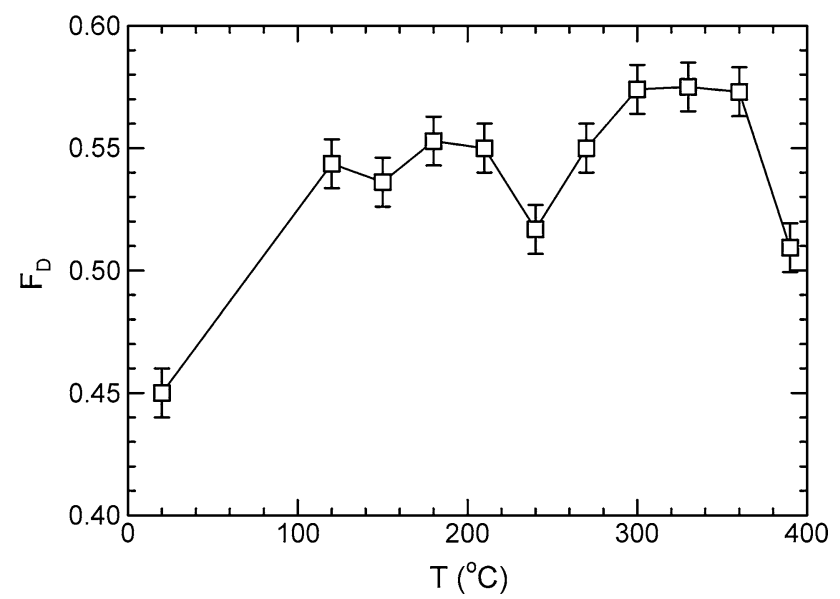

Fig. 6-Temperature dependence of the fraction of positrons trapped at defects calculated by Eq. [3].

$$
\begin{aligned}
\rho(p)= & \left(1-F_{\mathrm{D}}\right)+F_{\mathrm{D}}\left(\xi_{\mathrm{Al}, \mathrm{D}} \rho_{\mathrm{Al}, \mathrm{D}}(p)+\xi_{\mathrm{Sc}, \mathrm{D}} \rho_{\mathrm{Sc}, \mathrm{D}}(p)\right. \\
& \left.+\xi_{\mathrm{Zr}, \mathrm{D}} \rho_{\mathrm{Zr}, \mathrm{D}}(p)+\xi_{\mathrm{Mn}, \mathrm{D}} \rho_{\mathrm{Mn}, \mathrm{D}}(p)\right) .
\end{aligned}
$$

In order to decompose the CDB ratio curve for the AlMnScZr alloy into various contributions, it is necessary to determine the ratio curves $\rho_{\mathrm{Al}, \mathrm{D}}(p), \rho_{\mathrm{Sc}, \mathrm{D}}(p)$, $\rho_{\mathrm{Zr}, \mathrm{D}}(p), \rho_{\mathrm{Mn}, \mathrm{D}}(p)$ for positrons trapped at vacancy-like defects in pure $\mathrm{Al}, \mathrm{Sc}, \mathrm{Zr}$, and $\mathrm{Mn}$ elements. Here we followed the approach developed by Somoza et al. ${ }^{[29]}$ and used heavily cold rolled high-purity $\mathrm{Al}, \mathrm{Sc}, \mathrm{Zr}$, and Mn specimens. LT investigations of these specimens revealed saturated positron trapping at dislocations. Thus CDB ratio curves measured in heavily cold rolled $\mathrm{Al}, \mathrm{Sc}, \mathrm{Zr}$, and $\mathrm{Mn}$ (plotted in Figure 7) can be used as fair approximations of $\rho_{\mathrm{Al}, \mathrm{D}}(p), \rho_{\mathrm{Sc}, \mathrm{D}}(p), \rho_{\mathrm{Zr}, \mathrm{D}}(p)$, and $\rho_{\mathrm{Mn}, \mathrm{D}}(p)$. From the comparison of Figures 1 and 7 , it can be seen that the ratio curves for the cold rolled reference specimens have similar features as those measured in the well-annealed specimens but are enhanced at low momentums $\left(p<5 \times 10^{-3} \mathrm{~m}_{0} \mathrm{c}\right)$ and lowered at the high momentum range $\left(p>10 \times 10^{-3} \mathrm{~m}_{0} \mathrm{c}\right)$. This is due to localization of the positron wave function at defects which reduces its overlap with high momentum core electrons.

The CDB ratio curves measured in the AlMnScZr alloy were fitted by Eq. [4] and the model curves which are plotted in Figure 4 by solid lines are in a satisfactory agreement with experimental points. The coefficients $\xi_{\mathrm{Sc}, \mathrm{D}}, \xi_{\mathrm{Zr}, \mathrm{D}}$, and $\xi_{\mathrm{Mn}, \mathrm{D}}$ were considered as free parameters in fitting. From fitting, we obtained that $\xi_{\mathrm{Mn}, \mathrm{D}}$ equals zero at all annealing temperatures up to $663 \mathrm{~K}$ $\left(390{ }^{\circ} \mathrm{C}\right)$. The temperature dependences of $\xi_{\mathrm{Sc}, \mathrm{D}}$ and $\xi_{\mathrm{Zr}, \mathrm{D}}$ obtained from fitting are plotted in Figure 8. There is relatively high probability that a positron trapped at a defect is annihilated by Sc electron already in the as-cast alloy. Since $\xi_{\mathrm{Sc}, \mathrm{D}}$ is much higher than the atomic Sc concentration in the alloy, this result testifies to significantly enhanced concentration of Sc in the vicinity of dislocations and indicates that $\mathrm{Sc}$ atoms segregate at

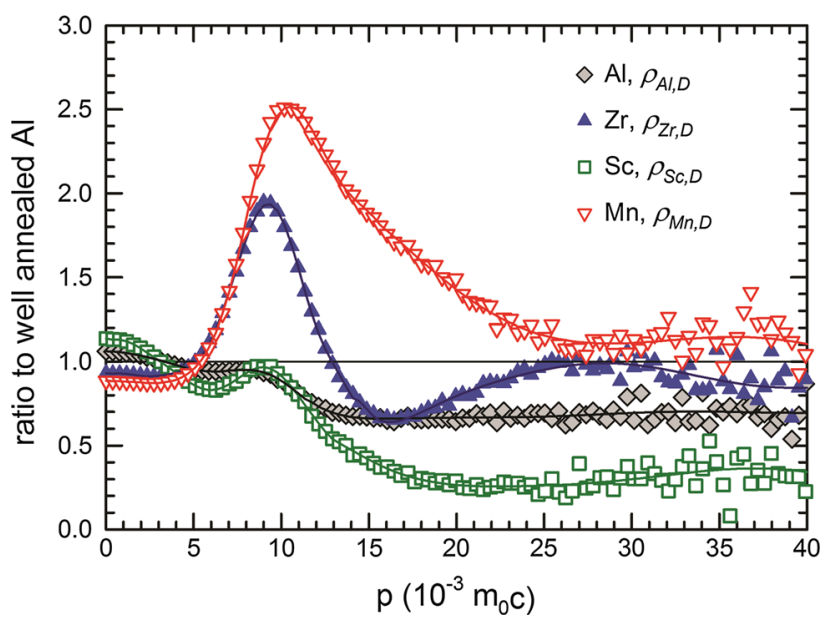

Fig. 7- CDB ratio curves for heavily cold rolled high-purity $\mathrm{Al}, \mathrm{Mn}$, $\mathrm{Sc}$, and $\mathrm{Zr}$.

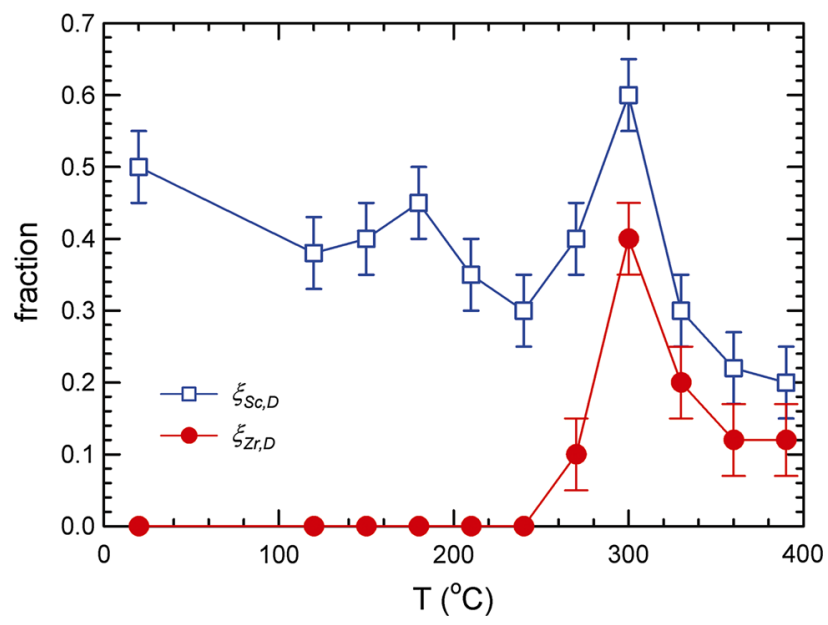

Fig. 8-Temperature dependence of the fractions $\xi_{\mathrm{Sc}, \mathrm{D}}$ and $\xi_{\mathrm{Zr}, \mathrm{D}}$ of positrons trapped at defects and annihilated by $\mathrm{Sc}$ and $\mathrm{Zr}$ electrons, respectively, obtained by fitting of $\mathrm{CDB}$ ratio curves of the Al$\mathrm{MnScZr}$ alloy by Eq. [4].

dislocations - dislocations are probably surrounded by solute $\mathrm{Sc}$ atoms in the as-cast state.

During the isochronal annealing, the probability that a trapped positron is annihilated by Sc electron varies and exhibits two local maxima at $453 \mathrm{~K}$ and $573 \mathrm{~K}$ $\left(180{ }^{\circ} \mathrm{C}\right.$ and $\left.300{ }^{\circ} \mathrm{C}\right)$ corresponding well to the temperatures when the two stages (I- and II-CDB stage) were observed at; cf. Figure 5. These maxima are caused by a contribution of positrons trapped at the new defects with local chemical environment enriched by Sc. These new defects are obviously associated with agglomerates of Sc solute atoms. The probability $\xi_{\mathrm{Zr}, \mathrm{D}}$ that a trapped positron will be annihilated by $\mathrm{Zr}$ electron remains negligible up to $513 \mathrm{~K}\left(240{ }^{\circ} \mathrm{C}\right)$. Annealing at higher temperatures causes an increase of $\xi_{\mathrm{Zr}, \mathrm{D}}$ which achieves its maximum at $573 \mathrm{~K}\left(300{ }^{\circ} \mathrm{C}\right)$, i.e., at the temperature where $\xi_{\mathrm{Sc}, \mathrm{D}}$ exhibits a maximum as well. This is the temperature corresponding to the position of the II-CDB stage in Figure 5. 


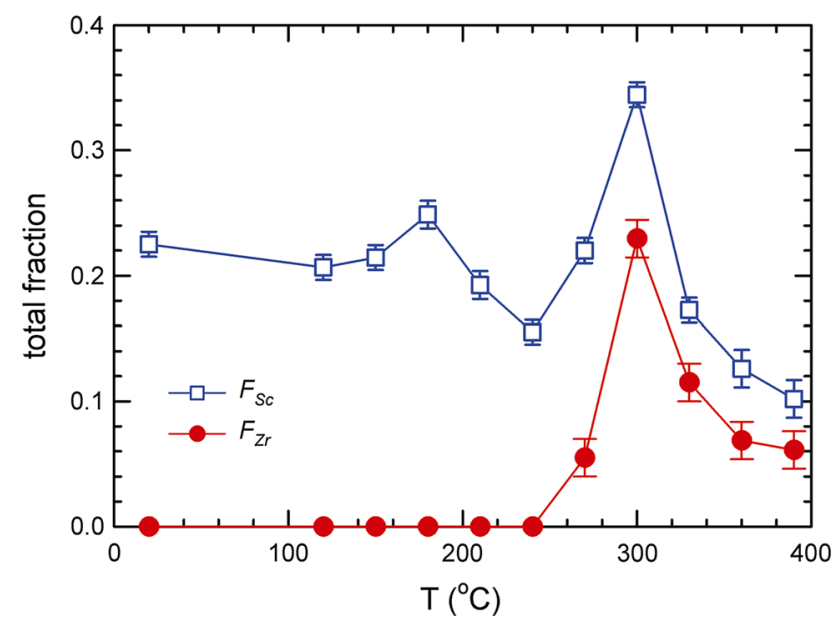

Fig. 9-Temperature dependence of the total fractions $F_{\mathrm{Sc}}, F_{\mathrm{Zr}}$ of positrons annihilated by $\mathrm{Sc}$ and $\mathrm{Zr}$ electrons, respectively.

Positrons trapped at dislocations and at defects associated with $\mathrm{Sc}$ clusters both contribute to the probability $\xi_{\mathrm{Sc}, \mathrm{D}}$. The probability that positrons trapped at dislocations will be annihilated by $\mathrm{Sc}$ electrons decreases with temperature most probably due to diffusion of $\mathrm{Sc}$ atoms along dislocations and their agglomeration into Sc clusters. At $453 \mathrm{~K}\left(180^{\circ} \mathrm{C}\right)$, it is lower than the probability that positrons trapped at defects associated with solute clusters will be annihilated by Sc electrons. The coarsening of the Sc clusters above $\sim 453 \mathrm{~K}\left(180{ }^{\circ} \mathrm{C}\right)$ is accompanied by an improvement of the structural perfection of the clusters and gradual disappearance of defects. This leads to observed reduction of the fraction $\xi_{\mathrm{Sc}, \mathrm{D}}$ of positions annihilated by Sc electrons. Similar effect leads to decrease of $\xi_{\mathrm{Sc}, \mathrm{D}}$ and $\xi_{\text {Zr,D }}$ after annealing above $573 \mathrm{~K}\left(300{ }^{\circ} \mathrm{C}\right)$.

Temperature dependence of the probabilities $\xi_{\mathrm{Sc}, \mathrm{D}}$ and $\xi_{\mathrm{Zr}, \mathrm{D}}$ gives information about changes of concentration of $\mathrm{Sc}$ and $\mathrm{Zr}$ in the vicinity of defects but do not reflect changes in defect density. The total fraction of positrons annihilated by $\mathrm{Sc}$ electrons $F_{\mathrm{Sc}}=F_{\mathrm{f}} \xi_{\mathrm{Sc}, \mathrm{f}}+$ $F_{\mathrm{D}} \xi_{\mathrm{Sc}, \mathrm{D}}$ is a quantity which reflects not only the variations of Sc content in the vicinity of defects but also changes of the defect density. Since $\xi_{\mathrm{Sc}, \mathrm{f}}$ is negligible, it can be calculated simply as $F_{\mathrm{Sc}}=F_{\mathrm{D}} \xi_{\mathrm{Sc}, \mathrm{D}}$. Similarly the total fraction of positrons annihilated by $\mathrm{Zr}$ electrons is $F_{\mathrm{Zr}}=F_{\mathrm{D}} \xi_{\mathrm{Zr}, \mathrm{D}}$. The fractions $F_{\mathrm{Sc}}$ and $F_{\mathrm{Zr}}$ are plotted in Figure 9 as a function of the annealing temperature and their behavior is similar to that of temperature development of the probabilities $\xi_{\mathrm{Sc}, \mathrm{D}}$ and $\xi_{\mathrm{Zr}, \mathrm{D}}$ plotted in Figure $8 . F_{\mathrm{Sc}}$ increases and reaches local maximum at $453 \mathrm{~K}\left(180^{\circ} \mathrm{C}\right)$ which indicates that clustering of Sc atoms takes place and positrons are trapped at vacancy-like defects associated with $\mathrm{Sc}$ clusters. After annealing above $\sim 453 \mathrm{~K}\left(180^{\circ} \mathrm{C}\right) F_{\mathrm{Sc}}$ decreases most probably due to coarsening of Sc clusters but annealing above $\sim 513 \mathrm{~K}\left(240{ }^{\circ} \mathrm{C}\right)$ leads again to an increase of $F_{\mathrm{Sc}}$ which reaches maximum $573 \mathrm{~K}\left(300{ }^{\circ} \mathrm{C}\right)$. The increase of $F_{\mathrm{Sc}}$ above $513 \mathrm{~K}\left(240{ }^{\circ} \mathrm{C}\right)$ is accompanied by a rise of $F_{\mathrm{Zr}}$. This gives evidence that $\mathrm{Zr}$ atoms are incorporated into Sc-rich dispersoids. Most probably $\mathrm{Zr}$ atoms segregate at the interfaces between the Sc-

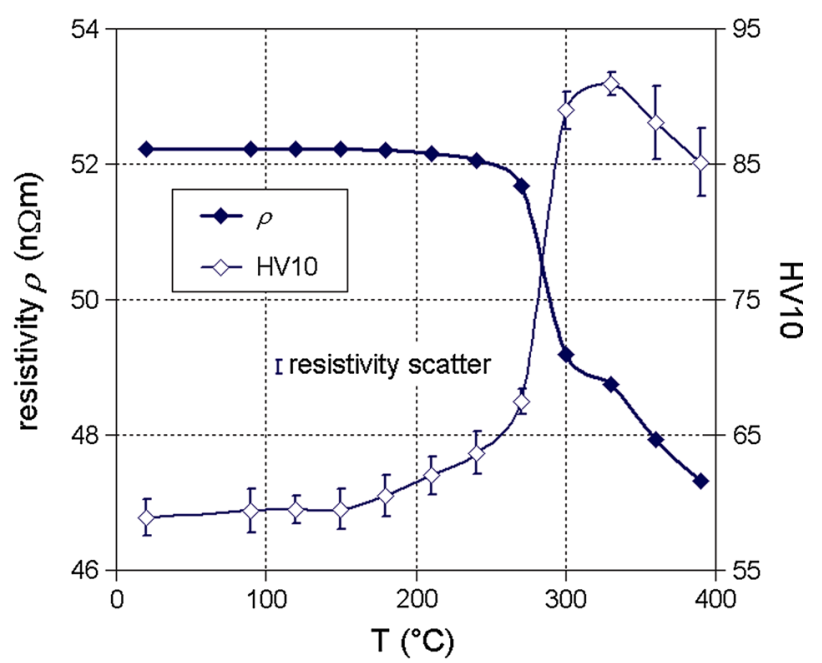

(a)

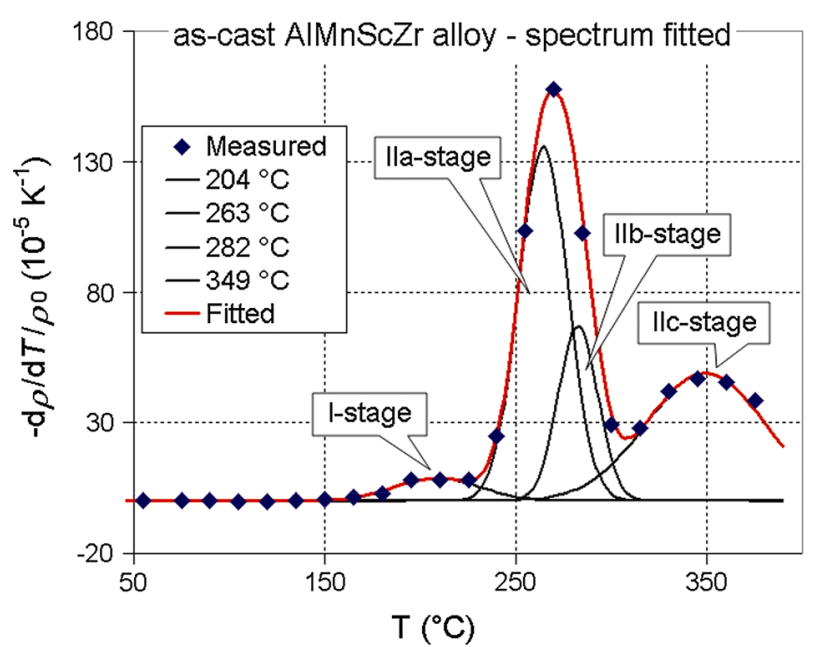

(b)

Fig. 10 - (a) Temperature dependence of electrical resistivity and hardness HV10 of the AlMnScZr alloy, (b) electrical resistivity spectrum constructed from resistivity data in the panel (a). The thick solid red line shows a model curve calculated as superposition of Gaussian peaks corresponding to individual stages (thin black lines) (Color figure online).

rich dispersoids and the $\mathrm{Al}$ matrix as it was also previously reported..$^{[9,14-17]}$ Above $\sim 573 \mathrm{~K}\left(300{ }^{\circ} \mathrm{C}\right)$ coarsening of the Sc-rich precipitates surrounded by a Zr-rich shell takes place leading to a decrease of their density and a drop of both $F_{\mathrm{Sc}}$ and $F_{\mathrm{Zr}}$.

\section{Electrical Resistivity and Hardness Study During Isochronal Annealing}

Electrical resistivity and hardness isochronal annealing curves are shown in Figure 10(a). The curves closely resemble those published in Reference 5 Only very small resistivity changes were observed up to $483 \mathrm{~K}\left(210{ }^{\circ} \mathrm{C}\right)$ but together with an insignificant increase of hardness. The main feature visible in the temperature dependence of electrical resistivity is the pronounced decrease above $483 \mathrm{~K}\left(210^{\circ} \mathrm{C}\right)$ accompanied by hardening caused undoubtedly by some precipitation process. Negative 
numerical derivative (spectrum curve) of the electrical resistivity annealing curve of Figure 10(a) is plotted in Figure 10(b). As a matter of fact the spectrum curve is a sum of derivatives of individual S-shape curves that reflect the volume fraction development of the individual phases precipitating. ${ }^{[19]}$ The resistivity spectrum can be then described as a superposition of Gaussian peaks each representing a stage corresponding to precipitation of a certain phase. Least square fitting of the resistivity spectrum of the AlMnScZr alloy by Gaussians revealed four stages shown in Figure 10(b). The spectrum curve exhibits one weak stage with a maximum at $\sim 477 \mathrm{~K}$ $\left(204{ }^{\circ} \mathrm{C}\right.$ ) (labeled as I-stage) followed by three another positive stages at $\sim 536 \mathrm{~K}\left(263{ }^{\circ} \mathrm{C}\right)$ (IIa-stage), at $\sim 555 \mathrm{~K}$ $\left(282{ }^{\circ} \mathrm{C}\right)$ (IIb-stage), and at $\sim 622 \mathrm{~K}\left(349^{\circ} \mathrm{C}\right)$ (IIc-stage). No negative resistivity stages were observed; therefore, no dissolution of clusters or phases developed in the process of isochronal annealing took place. It indicates the impotence of pre-precipitation and early precipitation processes in the development of phase in morphology leading to the high strengthening.

\section{DISCUSSION}

The I-CDB stage detected by $\mathrm{CDB}$ at $\sim 453 \mathrm{~K}$ $\left(180{ }^{\circ} \mathrm{C}\right)$ (Figure 5) corresponds to the weak I-stage in the electrical resistivity spectrum (Figure 10(b)). Since $F_{\mathrm{Sc}}$ reaches its local maximum in this stage, while $F_{\mathrm{Zr}}$ remains zero the stage can be ascribed to the clustering of dissolved Sc atoms. Increase of hardness at $\sim 453 \mathrm{~K}$ $\left(180{ }^{\circ} \mathrm{C}\right)$ in Figure 10 (a) indicates that Sc-rich clusters are more efficient obstacles for dislocation motion than dissolved Sc atoms. The Sc-rich clusters represent precursors for the $\mathrm{Al}_{3} \mathrm{Sc}$-phase precipitates formed at higher temperatures. ${ }^{[15-17]}$ Since diffusion of Sc solutes occurs via vacancy mechanism, the Sc-rich dispersoids are likely associated with vacancies particularly in early stages of their formation. Positrons trapped at these vacancies are annihilated by Sc electrons preferentially and it leads to an increase of $F_{\mathrm{Sc}}$. A similar effect, the formation of small $\mathrm{Sn}$ and Gd clusters associated with vacancies, was observed in References 40, 41. Figures 5, 8, 9, and 10a show that Sc-rich clusters are formed already at temperatures above $\sim 423 \mathrm{~K}\left(150{ }^{\circ} \mathrm{C}\right)$, i.e., at significantly lower temperature than in the previous studies, where the onset of clustering of Sc solutes was found at $\sim 563 \mathrm{~K}\left(290^{\circ} \mathrm{C}\right)$ by APT. ${ }^{[15]}$ The diffusivity of Sc solutes might be enhanced by quenched-in vacancies bound to these elements. Moreover, since Sc atoms segregated at dislocations already in the as-cast alloy their diffusivity is likely enhanced also by dislocations (pipe diffusion).

The fraction of trapped positrons annihilated by Sc electrons $\xi_{\mathrm{Sc}, \mathrm{D}}$ plotted in Figure 8 is proportional to the fraction of Sc atoms surrounding vacancies associated with the solute clusters. But it is not merely equal to this value since the probability that a positron will be annihilated by a Sc electron is higher than the probability that it will be annihilated by an Al electron. The reason is that $\mathrm{Sc}$ has higher number of core electrons than Al. Hence, the probability that a positron will be annihilated by a Sc electron is higher than the probability that it will annihilated by an Al electron. As a rough approximation one can assume that the fraction of positrons annihilated by Sc electrons is $\xi_{\mathrm{Sc}, \mathrm{D}} \sim c_{\mathrm{Sc}, \mathrm{D}}$ $Z_{\mathrm{Sc}} / Z_{\mathrm{Al}}$, where $c_{\mathrm{Sc}, \mathrm{D}}$ is the fraction of $\mathrm{Sc}$ atoms surrounding the vacancy and the symbols $Z_{\mathrm{Sc}}, Z_{\mathrm{Al}}$ denote the atomic number for $\mathrm{Sc}$ and $\mathrm{Al}$, respectively. Inserting the value $\xi_{\mathrm{Sc}, \mathrm{D}} \sim 0.45$ measured at $453 \mathrm{~K}$ $\left(180{ }^{\circ} \mathrm{C}\right.$ ) (see Figure 8 ) and $Z_{\mathrm{Sc}}=21, Z_{\mathrm{Al}}=13$ one obtains $c_{\mathrm{Sc}, \mathrm{D}} \sim 0.28$. This value is comparable with $1 / 3$ which is the fraction of $\mathrm{Sc}$ atoms surrounding $\mathrm{Al}$ vacancy in the $\mathrm{Ll}_{2}$ structure. Similarly for $\mathrm{Zr}$ solutes $\xi_{\mathrm{Zr}, \mathrm{D}} \sim c_{\mathrm{Zr}, \mathrm{D}} Z_{\mathrm{Zr}} / Z_{\mathrm{Al}}$, where $c_{\mathrm{Zrc}, \mathrm{D}}$ is the fraction of $\mathrm{Zr}$ atoms surrounding the vacancy and $Z_{\mathrm{Zr}}=38$. Using $\xi_{\text {Zr,D }} \sim 0.40$ measured at $573 \mathrm{~K}\left(300{ }^{\circ} \mathrm{C}\right)$ one obtains $c_{\mathrm{Zr}, \mathrm{D}} \sim 0.14$.

It has to be noted that the positron affinity for Sc is higher in magnitude (i.e., more negative) than that for the Al matrix. ${ }^{[42]}$ Hence, even defects-free coherent Sc particles would be able to confine positrons. However, positrons trapped at such defect-free coherent Sc particles would contribute to LT spectrum by a component with the lifetime corresponding to the Sc bulk lifetime, i.e., 196 ps. ${ }^{[34]}$ Obviously the lifetime $\tau_{2}$ plotted in Figure 3(a) is substantially higher than the bulk Sc lifetime. This testifies that Sc clusters formed in the alloy are not defect-free and positron trapping occurs at vacancy-like defects associated with these clusters which are significantly deeper traps than defect-free Sc particles.

The positron affinity for the other alloying elements $(\mathrm{Mn}, \mathrm{Zr})$ is lower in magnitude compared to $\mathrm{Al}^{[42]}$ Hence, positron trapping in $\mathrm{Mn}$ or $\mathrm{Zr}$ particles in the $\mathrm{Al}$ matrix is possible only if these particles contain some open volume defects. This means that defect-free coherent $\mathrm{Mn}$ or $\mathrm{Zr}$ particles if present in the sample would be unnoticed by PAS.

Modeling the electrical resistivity evolution in the AlSc-based alloys using cluster dynamics predicted the time evolution of the size distribution supposing that the excess resistivity of atomic fraction of clusters is proportional to the number density of clusters, where the proportionality coefficient being supposed constant and equal to the resistivity contribution of monomers. ${ }^{[2]}$ The model assumes that the resistivity increase during coarsening arises mainly from large clusters $\left(n_{\mathrm{Sc}}\right.$ $\geq 11$ ). However, a resistivity increase due to pre-precipitation stages has never been observed experimentally in Al-Sc-based alloys, and only solutes and small clusters $n_{\mathrm{Sc}} \leq 10$ (dimmers mainly) were present at most after short annealing times up to $10^{4} \mathrm{~s}$ at temperatures below $\sim 503 \mathrm{~K} \quad\left(230{ }^{\circ} \mathrm{C}\right) .{ }^{[22]}$ The weak resistivity decrease observed in this work, corresponding to the resistivity stage at $\sim 473 \mathrm{~K}\left(200{ }^{\circ} \mathrm{C}\right)$, is very probably connected with Sc atoms clustering. This behavior of resistivity can be easily understood since formation of small Sc clusters decreases the concentration of $\mathrm{Sc}$ solutes in the $\mathrm{Al}$ matrix. Similar resistivity decrease was observed in our previous work in the ternary AlScZr alloy annealed up to $\sim 483 \mathrm{~K}\left(210^{\circ} \mathrm{C}\right) .{ }^{[17]}$ It is also worth to notice that the effect of thermal vacancies on the resistivity is too small to be detected up to $\sim 673 \mathrm{~K}\left(400^{\circ} \mathrm{C}\right) .{ }^{[17,43,44]}$ 


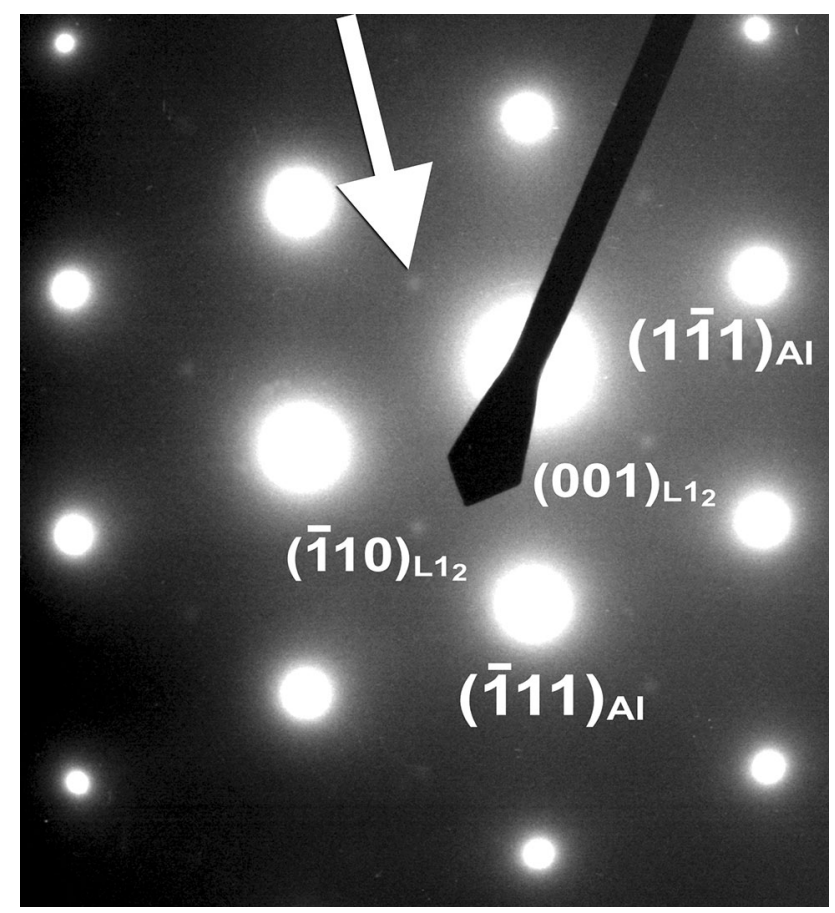

Fig. 11 - Selected area electron diffraction pattern of $[110]_{\mathrm{Al}}$ zone showing weak reflections from fine $\mathrm{Sc}, \mathrm{Zr}$-containing particles with $\mathrm{L}_{2}$ structure in the AlMnScZr alloy annealed at $573 \mathrm{~K}\left(300^{\circ} \mathrm{C}\right)$.

It can be seen from Figures 8, 9, and 10(b) that no Zrresponse to annealing was observed up to $\sim 513 \mathrm{~K}$ $\left(240{ }^{\circ} \mathrm{C}\right)$. This is in accordance with lower diffusivity of $\mathrm{Zr}$ in $\mathrm{Al}$ matrix. ${ }^{[22,45]}$ The second annealing stage (II-CDB stage as well as II-stage in resistivity spectrum), which appears above this temperature (see in Figures 5, 8,9 , and $10(\mathrm{~b})$ ), is connected not only with an increase of $F_{\mathrm{Sc}}$ but also with a rise of $F_{\mathrm{Zr}}$.

It was shown ${ }^{[14,15]}$ that the Sc-rich clusters subsequently transform into the $\mathrm{Al}_{3} \mathrm{Sc}$ particles with a $\mathrm{Ll}_{2}$ structure. Afterward $\mathrm{Zr}$ atoms are found to segregate to $\mathrm{Al}_{3} \mathrm{Sc} / \alpha$-Al matrix interfaces. An enhanced concentration of $\mathrm{Zr}$ around the dispersoids was observed by APT after annealing above $\sim 673 \mathrm{~K}\left(400{ }^{\circ} \mathrm{C}\right)$ only. ${ }^{[15,46,47]}$ However, a high fraction of positrons annihilated by $\mathrm{Zr}$ electrons $F_{\mathrm{Zr}} \sim 0.23$ observed already at $573 \mathrm{~K}\left(300^{\circ} \mathrm{C}\right)$ (see Figure 9) indicates that diffusion of $\mathrm{Zr}$ atoms to the interfaces of Sc-rich dispersoids takes place already at temperatures above $\sim 513 \mathrm{~K}\left(240{ }^{\circ} \mathrm{C}\right)$. This is supported by the electrical resistivity results as decomposition of the resistivity spectrum in Figure $10 \mathrm{~b}$ revealed two stages at $\sim 536 \mathrm{~K}\left(263{ }^{\circ} \mathrm{C}\right)$ (IIa-stage) and $\sim 555 \mathrm{~K}$ $\left(282{ }^{\circ} \mathrm{C}\right)$ (IIb-stage) which can be ascribed to the $\mathrm{Al}_{3} \mathrm{Sc}$-phase formation and formation of $\mathrm{Zr}$-enriched shell of these dispersoids, respectively.

A very fine dispersion of small particles with average diameter less than $\sim 1 \mathrm{~nm}$ and giving a very weak bright field contrast were observed by TEM after annealing up to $573 \mathrm{~K}\left(300{ }^{\circ} \mathrm{C}\right)$. Therefore TEM picture is not shown but the selected area ED patterns from the alloy confirm superstructure reflections of the $\mathrm{Ll}_{2}$ structure (Figure 11). Thus the pronounced hardening at $\sim 573 \mathrm{~K}\left(300^{\circ} \mathrm{C}\right)$ and the main resistivity decrease has its origin in the precipitation of the $\mathrm{Al}_{3} \mathrm{Sc}$ dispersoids with subsequent formation of $\mathrm{Zr}$-rich shell. Similar situation was observed at $573 \mathrm{~K}$ $\left(300{ }^{\circ} \mathrm{C}\right)$ in the Al-Sc-based alloys. ${ }^{[5,17]}$

Using the known contributions of $\mathrm{Sc}$ and $\mathrm{Zr}$ to resistivity ${ }^{[2,48]}$ and the resistivity drop in the IIb-stage the decrease of the solute concentrations in the matrix was estimated as $\Delta c_{\mathrm{Sc}}=(0.082 \pm 0.004)$ at. pct and $\Delta c_{\mathrm{Zr}}=(0.023 \pm 0.004)$ at. pct for $\mathrm{Sc}$ and $\mathrm{Zr}$, respectively.

The study of $\mathrm{Al}_{3}(\mathrm{Sc}, \mathrm{Zr})$ dispersoids evolution kinetics showed that $\mathrm{Zr}$ content in the outer shell decreases during growth at short annealing times ( $<2$ hours) at temperatures higher then $623 \mathrm{~K}\left(350{ }^{\circ} \mathrm{C}\right) .{ }^{[46]}$ Reduction of $\mathrm{Sc}$ content in the nearest neighborhood of growing dispersoid connected with preceding Sc rich core development does not lead to the zero content of Sc in the shell. ${ }^{[14,15,47]}$ Thus the decrease of electrical resistivity above $573 \mathrm{~K}\left(300{ }^{\circ} \mathrm{C}\right)$ [and corresponding spectrum stage at $\left.\sim 613 \mathrm{~K}\left(340^{\circ} \mathrm{C}\right)\right]$ as well as the hardness decrease is connected with coarsening of the $\mathrm{Al}_{3}(\mathrm{Sc}, \mathrm{Zr})$ particles. This also leads to an increase in the mutual distance of the precipitates, which reduces the probability of the positron trapping (see Figures 3 and 5).

From the known contributions of $\mathrm{Sc}$ and $\mathrm{Zr}$ to resistivity, ${ }^{[2,48]}$ the further decrease of solute concentrations in the resistivity IIc-stage at $\sim 622 \mathrm{~K}\left(349^{\circ} \mathrm{C}\right)$ was estimated to be $\Delta c_{\mathrm{Sc}}=(0.012 \pm 0.003)$ at. pct and $\Delta c_{\mathrm{Zr}}=(0.005 \pm 0.003)$ at. pct for $\mathrm{Sc}$ and $\mathrm{Zr}$, respectively. Taking into account the error due to missing the last points of the Gaussian peak at $\sim 622 \mathrm{~K}\left(349{ }^{\circ} \mathrm{C}\right)$ one can not exclude the possibility that the calculated error can be higher. However, these values can be thought as realistic ones considering the composition of the studied alloys and solubility limits of $\mathrm{Sc}$ and $\mathrm{Zr}$ at comparable temperatures. ${ }^{[17]}$

\section{CONCLUSIONS}

Results of positron lifetime spectroscopy, CDB, electrical resistometry, hardness measurements and microstructure investigations of the dilute as-cast AlMnScZr alloy can be summarized as follows:

1. Sc atoms segregate at (or near of) dislocations in the as-cast AlMnScZr alloy.

2. Clustering of $\mathrm{Sc}$ solute occurs at temperatures above $\sim 423 \mathrm{~K}\left(150{ }^{\circ} \mathrm{C}\right)$. Sc-rich regions are associated with vacancies particularly in the early stages of their formation.

3. $\mathrm{Zr}$ solutes migration starts above $\sim 513 \mathrm{~K}\left(240{ }^{\circ} \mathrm{C}\right)$ contributing to the development of the $\mathrm{Sc}, \mathrm{Zr}$-containing particles with the $\mathrm{L} 1_{2}$ structure.

4. The hardening peak at $\sim 573 \mathrm{~K}\left(300^{\circ} \mathrm{C}\right)$ is caused by the $\mathrm{Al}_{3}(\mathrm{Sc}, \mathrm{Zr})$ particles with a complex coreshell structure.

5. $\mathrm{Mn}$ solutes are not involved in the precipitation processes up to $\sim 673 \mathrm{~K}\left(400{ }^{\circ} \mathrm{C}\right)$ as the contribution of trapped positrons annihilated by $\mathrm{Mn}$ electrons was negligible. 


\section{ACKNOWLEDGMENTS}

This work was supported by The Czech Science Foundation (GACR) under Grant Number P108-12G043. The work was also a part of activities of the Charles University Research Centre "Physics of Condensed Matter and Functional Materials".

\section{REFERENCES}

1. E.A. Marquis and D.N. Seidman: Acta Mater., 2005, vol. 53, pp. 4259-68. DOI:10.1016/j.actamat.2005.05.025.

2. L.S. Toropova, D.G. Eskin, M.L. Kharakterova, and T.V. Dobatkina: Advanced Aluminium Alloys Containing Scandium-Structure and Properties, Gordon and Breach Science Publisher, Amsterdam, 1998.

3. J. Røyset and R. Ryum: Int. Mater. Rev., 2005, vol. 50, pp. 19-44. DOI: $10.1179 / 174328005 X 14311$

4. M. Vlach, I. Stulíková, B. Smola, and N. Žaludová: Mater. Charact., 2010, vol. 61, pp. 1400-05. DOI:10.1016/j.matchar.2010.10.006.

5. M. Vlach, I. Stulíková, B. Smola, J. Piesova, H. Cisarova, S. Danis, J. Plasek, R. Gemma, D. Tanprayoon, and V. Neubert: Mater. Sci. Eng. A, 2012, vol. 548, pp. 27-32. DOI:10.1016/ j.msea.2012.03.063.

6. Z. Jia, J. Røyset, J.K. Solberg, and Q. Liu: Trans. Nonferrous Met. Soc. China, 2012, vol. 22, pp. 1866-71. DOI:10.1016/S10036326(11)61399-X.

7. M.M.R. Jaradeh and T. Carlberg: J. Mater. Sci. Technol., 2011, vol. 27, pp. 615-27. DOI:10.1016/S1005-0302(11)60116-3.

8. Z. Zhou, B. Wu, S. Dou, C. Zhao, Y. Xiong, Y. Wu, S. Yang, and Z. Wei: Metall. Mater. Trans. A, 2014, vol. 45A, pp. 1720-35. DOI:10.1007/s11661-013-2117-9.

9. C. Booth-Morrison, D.C. Dunand, and D.N. Seidman: Acta Mater., 2011, vol. 59, pp. 7029-42. DOI:10.1016/j.actamat.2011.07.057.

10. P. Cavaliere: J. Mater. Sci., 2006, vol. 41, pp. 4299-4302. DOI:10.1007/s10853-006-6996-7.

11. C. Booth-Morrison, D.N. Seidman, and D.C. Dunand: Acta Mater., 2012, vol. 60, pp. 3643-54. DOI:10.1016/j.actamat.2012.02.030.

12. W.W. Zhou, B. Cai, W.J. Li, Z.X. Liu, and S. Yang: Mater. Sci. Eng. A, 2012, vol. 552, pp. 353-58. DOI:10.1016/j.msea.2012.05.051.

13. N.A. Belov, A.N. Alabin, and I.A. Matveeva: J. Alloys Compd., 2014, vol. 583, pp. 206-13. DOI:10.1016/j.jallcom.2013.08.202.

14. B. Forbord, W. Lefebvre, F. Danoix, H. Hallem, and K. Marthinsen: Scripta Mater., 2004, vol. 51, pp. 333-37. DOI:10.1016/j.scriptamat.2004.03.033.

15. W. Lefebvre, F. Danoix, H. Hallem, B. Forbord, A. Bostel, and K. Marthinsen: J. Alloys Compd., 2009, vol. 470, pp. 107-10. DOI:10.1016/j.jallcom.2008.02.043.

16. N.Q. Vo, D.C. Dunand, and D.N. Seidman: Acta Mater., 2014, vol. 63, pp. 73-85. DOI:10.1016/j.actamat.2013.10.008.

17. M. Vlach, I. Stulíková, B. Smola, N. Žaludová, and J. Černá: $J$. Alloys Compd., 2010, vol. 492, pp. 143-48. DOI:10.1016/j.jallcom.2009.11.126

18. H.I. Aaronson: Lectures on the Theory of Phase Transformations, AIME, New York, 1975.

19. I. Stulikova and B. Smola: Solid State Phenom., 2008, vol. 138, pp. 57-62. DOI:10.4028/www.scientific.net/SSP.138.57.

20. M. Vlach, B. Smola, I. Stulíková, and V. Očenášek: Int. J. Mater. Res., 2009, vol. 100, pp. 420-23. DOI:10.3139/146.110022.

21. P.L. Rossiter: The Electrical Resistivity of Metals and Alloys, Cambridge University Press, Cambridge, 1987.
22. E. Clouet and A. Barbu: Acta Mater., 2007, vol. 55, pp. 391-400. DOI:10.1016/j.actamat.2006.08.021.

23. H.H. Jo and S.I. Fujikawa: Mater. Sci. Eng. A, 1993, vol. 171, pp. 151-61. DOI:10.1016/0921-5093(93)90401-Y.

24. S.I. Fujikawa, M. Sugaya, H. Takei, and K.I. Hirano: J. Less Common Met., 1979, vol. 63, pp. 87-97. DOI:10.1016/00225088(79)90211-X.

25. C. Watanabe, T. Kondo, and R. Monzen: Metall. Mater. Trans. A, 2004, vol. 35A, pp. 3003-08. DOI:10.1007/s11661-004-0247-9.

26. P. Hautojärvi and C. Corbel: Proceedings of the International School of Physics "Enrico Fermi", IOS Press, Amsterdam, 1995.

27. P. Asoka-Kumar, M. Alatalo, V.J. Ghosh, A.C. Kruseman, B. Nielsen, and K.G. Lynn: Phys. Rev. Lett., 1996, vol. 77, pp. 20972100. DOI:10.1103/PhysRevLett.77.2097.

28. S.M. He, N.H. van Dijk, H. Schut, E.R. Peekstok, and S. van der Zwaag: Phys. Rev. B, 2010, vol. 81, p. 094103. DOI: 10.1103/PhysRevB.81.094103.

29. A. Somoza, M.P. Petkov, and K.G. Lynn: Phys. Rev. B, 2002, vol. 65, p. 094107. DOI:10.1103/PhysRevB.65.094107.

30. F. Bečvář, J. Č́žek, I. Procházka, and J. Janotová: Nucl. Inst. Methods Phys. Res. A, 2005, vol. 539, pp. 372-85. DOI:10.1016/ j.nima.2004.09.031.

31. I. Prochazka, I. Novotny, and F. Becvar: Mater. Sci. Forum, 1997, vols. 255-257, pp. 772-74. DOI:10.4028/www.scientific.net/ MSF.255-257.772.

32. J. Č́žžek, M. Vlček, and I. Procházka: Nucl. Inst. Methods Phys. Res. A, 2010, vol. 623, pp. 982-94. DOI:10.1016/ j.nima.2010.07.046.

33. M. Hájek, J. Veselý, and M. Cieslar: Mater. Sci. Eng. A, 2007, vol. 462, pp. 339-42. DOI:10.1016/j.msea.2006.01.175.

34. J.M.C. Robles, E. Ogando, and F. Plazaola: J. Phys. Condens. Matter, 2007, vol. 19, p. 176222. DOI:10.1088/0953-8984/ $19 / 17 / 176222$.

35. R.N. West: in Positrons in Solids, P. Hautojärvi, ed., Springer, Berlin, 1979. DOI:10.1007/978-3-642-81316-0_3.

36. J. Č́žžek, I. Procházka, T. Kmječ, and P. Vostrý: Phys. Status Solid $A$, 2000, vol. 180, pp. 439-58. DOI:10.1002/1521396X(200008)180:2<439::AID-PSSA439>3.0.CO;2-9.

37. H. Murakami, T. Endo, and I. Matsuda: Phys. Rev. B, 1991, vol. 44, p. 2504. DOI:10.1103/PhysRevB.44.2504.

38. G. Dlubek: Mater. Sci. Forum, 1987, vols. 13-14, pp. 11-32. DOI:10.4028/www.scientific.net/MSF.13-14.11.

39. L.C. Smedskjaer, M. Manninen, and M.J. Fluss: J. Phys. F, 1980, vol. 10, pp. 2237-49. DOI:10.1088/0305-4608/10/10/019.

40. J. Ć́̇̌zek, O. Melikhova, I. Procházka, J. Kuriplach, I. Stulíková, P. Vostrý, and J. Faltus: Phys. Rev. B, 2005, vol. 7, p. 064106. DOI:10.1103/PhysRevB.71.064106.

41. J. Čížek, I. Procházka, B. Smola, I. Stulíková, R. Kužel, Z. Matěj, and V. Cherkaska: Phys. Status Solid A, 2006, vol. 203, pp. 46677. DOI: $10.1002 /$ pssa.200521483.

42. M.J. Puska, P. Lanki, and R.M. Nieminen: J. Phys. Condens. Matter, 1989, vol. 1, pp. 6081-93.

43. M. Doyama and J.S. Koehler: Phys. Rev., 1964, vol. 134, pp. A522-29. DOI:10.1103/PhysRev.134.A522.

44. K.M. Carling, G. Wahnström, T.R. Mattsson, N. Sandberg, and G. Grimvall: Phys. Rev. B, 2003, vol. 67, p. 054101. DOI: 10.1103/PhysRevB.67.054101

45. K.E. Knipling, D.C. Dunand, and D.N. Seidman: Int. J. Mater. Res., 2006, vol. 97, pp. 246-65. DOI:10.3139/146.101249.

46. A. Deschamps, E. Lae, and P. Guyot: Acta Mater., 2007, vol. 55, pp. 2775-83. DOI:10.1016/j.actamat.2006.12.015.

47. A. Tolley, V. Radmilovic, and U. Dahmen: Scripta Mater., 2005, vol. 52, pp. 621-25. DOI:10.1016/j.scriptamat.2004.11.021.

48. P. Olafsson, R. Sandstrom, and A.J. Karlsson: J. Mater. Sci., 1997, vol. 32, pp. 4383-90. DOI:10.1023/A:1018680024876. 